\title{
AVALIAÇÃO DE APROVEITAMENTO DOS RESÍDUOS AGRÍCOLAS PARA A PRODUÇÃO DE BRIQUETES ECOLÓGICOS
}

\section{EVALUATION OF AGRICULTURAL WASTE RECOVERY FOR ECOLOGICAL BRIQUETTES PRODUCTION}

\author{
Claudio Roberto Burkot ${ }^{1}$; Rudy de Barros Ahrens ${ }^{2}$ \\ ${ }^{1}$ Faculdades Integradas do Centro de Ensino Superior dos Campos Gerais -CESCAGE Ponta Grossa, \\ claudioburkot@hotmail.com ; rudy_barros@hotmail.com
}

\begin{abstract}
Resumo
Este trabalho avaliou o potencial de aproveitamento dos resíduos agrícolas em uma Cooperativa no Município de Ponta Grossa - Paraná. O trabalho expõe assuntos sobre agronegócio, resíduos agroindustriais, biomassa, energia renovável, lenha ecológica, reaproveitamento do resíduo e confecção de briquetes. Para uma maior compreensão e enriquecimento da pesquisa foram abordados assuntos como a origem de resíduos agrícolas, levantamento do volume de resíduos, transformação dos resíduos em briquetes, reaproveitamento da soja que por problemas no processo tenha sido descartada como lixo, avaliação da unidade existente na Cooperativa para briquetagem, posteriormente, foi avaliada a queima de briquetes com cavaco e lenha. O emprego de resíduos agricolas como biomassa combustivel para geração de energia transformados em briquetes pode ser uma solução para os problemas relacionados à sua disposição. Este estudo está baseado na técnica de pesquisa, classificando-a como básica, qualitativa exploratória, usando como procedimentos técnicos a revisão bibliográfica e o estudo de caso. Objetivou-se verificar a quantidade de resíduos que surge durante o processo de padronização de grãos na Cooperativa, analisando a estrutura existente na Cooperativa para confecção de briquetes e, por fim, avaliar a destinação dos resíduos que são transformados em briquetes. Com os resultados obtidos ficou comprovado que o reaproveitamento do resíduo, considerado como lixo, mostrou-se de extrema importância como energia renovável, gerando economia e com a destinação correta para a Cooperativa que trabalha com prestação de serviços na padronização das commodities, eliminouse passivel ambiental, agregando valor, como já tinha toda estrutura, a empresa revisou e comprou a máquina para briquetagem.
\end{abstract}

Palavras-chave: resíduos, briquetes, energia renovável.

\section{Introdução}

Diante dos novos desafios ambientais no agronegócio, o reaproveitamento de resíduos gerados no processo de padronização de commodities é discutido e defende-se o uso de fontes de energia renováveis. Não exclusivamente nos aspectos ambientais, no entanto, características peculiares como disponibilidade da qualidade, utilização do novo advento que surge como mercado 
de carbono e processos da tecnologia disponíveis fazem com que a energia produzida por biomassa seja viável nos quesitos de viabilidade econômica, ecológica e sociais dentro de toda cadeia de produção.

A cadeia bem sucedida do agronegócio é qualificada, tendo como princípio a agricultura, pecuária e pesca. Subsequentemente derivam as indústrias agroalimentares com ênfase na distribuição agrícola e alimentar, o comércio internacional e regional interno. Em todas essas fases existe o departamento de serviços de contribuição (BATALHA, 1997).

Para Moers et al., (2011), os resíduos da agroindústria surgem durante o beneficiamento ou processo de determinadas culturas, quanto os resíduos agrícolas suas características se definem como vegetais, os quais advêm do próprio campo, no andamento da colheita das commodities, as colhedoras recolhem plantas daninhas junto com os grãos e permanecem destroços da própria planta. Os Campos Gerais se destacam no cultivo agrícola ativo em grande escala e são os maiores fornecedores de grãos, quando processados ficam os resíduos como matéria-prima para a produção, no caso estudado, de briquetes, para eliminar o passivo ambiental e contribuir para os créditos de carbono e principalmente energia renovável.

Entre as fontes recuperáveis de energia, insere-se o grupo das biomassas, a de resíduos agrícolas oriundos do processo de padronização como: limpeza, secagem e armazenagem das commodities, esses resíduos se caracterizam entre sólidos orgânicos, restos de culturas que são recolhidas pelas colhedeiras que acompanham os grãos enviados para as unidades de armazenagem, gerando um passível ambiental enorme.

Ainda os resíduos podem ser determinados como qualquer material rejeitado ao longo da cadeia produtiva de beneficiamento e tornar-se um passivo ambiental para a empresa. No novo advento de reutilização e produção limpa, os resíduos deixam de ser um risco quando destinados para o reaproveitamento e passam a gerar receita se geridos perfeitamente, ou seja, reciclar o que pode ser reaproveitado e descartar de maneira adequada o que necessita ser descartado (VALE E GENTIL, 2008).

Outra fonte renovável de energia é o cavaco, o qual surge da colheita florestal, os resíduos originados devido ao beneficiamento da madeira diversificam devido à padronização das toras e do uso final, muito embora tenha a geração, sobretudo da serragem, desbastes e cepilhos, o que produz um passivo de grande valia para as madeireiras da região dos Campos Gerais.

O passivo ambiental possui amplo potencial energético sustentável para a geração de energia como fonte de calor. A briquetagem consiste no fluxo da secagem, moagem e compactação dos resíduos, saindo o briquete e sendo um produto sustentável em todos os seus aspectos.

De acordo com Junior et al. (2003), da destinação correta dos resíduos para produção 
energética surge o processamento de briquetagem, tal tecnologia pode ser ampliada com o reaproveitamento de distintos tipos de resíduos da agricultura, do setor madeireiro. Incide na compactação da massa de matéria-prima padronizada, transformando-a em um sólido cilíndrico e compacto, com alta densidade e posse calorífica, a briquetagem se torna, por isso, uma das escolhas tecnológicas mais corretas para uma melhor destinação e reaproveitamento dos resíduos de biomassa, gerando energia limpa.

Buscando avaliar a realidade sobre aproveitamento dos resíduos oriundos da própria cultura e de ervas daninhas, os quais acompanham os grãos até a padronização e se torna um problema para a Cooperativa, assim teve-se como objetivo geral avaliar o potencial de aproveitamento dos resíduos agrícolas em uma Cooperativa no Município de Ponta Grossa - Paraná para a produção de briquetes ecológicos com o objetivo de usar como fonte de energia juntamente com cavaco nos secadores de cereais. Como objetivo específico teve-se: a) Verificar a quantidade de resíduos que surge durante o processo de padronização de grãos na Cooperativa; b) Analisar a estrutura existente na Cooperativa para confecção de briquetes; c) Avaliar a destinação dos resíduos que são transformados em briquetes.

Desta forma, justifica-se a realização deste em função relevante pelo próprio contexto em que a cooperativa presta serviço de padronização de grãos gerando um grande volume de resíduos oriundos das próprias plantas e ervas daninhas. $\mathrm{O}$ estudo proporciona alternativas favoráveis ao meio ambiente e principalmente para a própria Cooperativa bem como redução de custos com a compra de lenha, produção de energia limpa, destacando o reaproveitamento dos resíduos agrícolas transformando em briquetes a chamada lenha ecológica.

No contesto geral, o Brasil é um grande produtor de commodities, os quais no processamento de padronização geram uma grande quantidade de resíduos. Os mesmos podem ser utilizados como fonte energética para vários fins. Ainda nossa cultura é muito acomodada, analisando a nível macro, deve-se considerar que não existem tecnologias ampliadas para o bom emprego de certas culturas, grandes potencialidades são deixadas para trás. Por outro lado, analisando é possível aproveitar certo percentual dos resíduos na aplicação, como no exemplo, ração animal, quando se trata de resíduos agrícolas.

Segundo Quirino (2003), a ideia de resíduos e todo e qualquer material inútil (lixo), sem o devido valor, precisa ser eliminada em condições seguras para evitar passivos ambientais para a empresa, evitando transtornos que, na grande maioria, empresas pagam para se livrar do problema.

Ainda Quirino (2003) descreveu os resíduos como sendo tudo aquilo que sobra da exploração ou do beneficiamento durante o processo de transformação até o produto acabado ou final. Sendo que, muitas empresas, proprietários, abandonam sem a devida destinação correta. 
Esses resíduos são classificados como sólidos, os quais concebem amplos desafios do século XXI, sinalizando o crescente avanço na geração e ainda o famoso déficit de recursos ambientais apropriados quanto ao término ou reutilização dos mesmos em outro processo. Além da crescente quantidade gerada, são descartados dia a dia no meio ambiente, o que torna mais complicados os processos de reutilização. Ainda o mesmo autor comenta que a alta geração dos resíduos, se não controlada, vai, somado aos conflitos ambientais acarretados pela disposição imprópria dos resíduos, causar um grande desperdício de matéria-prima de biomassa que poderia se transformar em energia (FARAGE, 2009).

De acordo com dados da Associação brasileira das indústrias de biomassa e energia renovável (ABIB, 2010), o Brasil tem uma ampla disponibilidade de resíduos florestais em torno de 70 milhões de toneladas, seguindo os não florestais, como o café, milho, feijão, soja e distintos; outros resíduos têm a condição de ser transformados em biomassa para geração de energia à nova geração.

Ainda na questão dos detritos, para o autor Rosa et al. (2011), os resíduos agroindustriais e agrícolas de processamento dos produtos de origem vegetal como oleaginosas, fibrosas, madeireiras e outros distintos produtos oferecem, em sua natureza, diversos destinos finais com valor agregado, que abrem oportunidades, como crédito de carbono, produção limpa, benefícios para as empresas que adotam essa oportunidade como no caso da produção de biomassa, transformando em energia.

Para o autor Goldemberg (2000), a energia, entre os distintos fatores, é um componente eficaz para o desenvolvimento humano, o mesmo relata ainda que o gasto de energia no mundo aumenta de ano a ano em grande escala e a perspectiva é triplicar nos próximos 30 anos, esse cenário leva a discorrer sobre as fontes renováveis para produção de energia, nas quais se insere a categoria das biomassas, destacando-se a dos resíduos vegetais.

Dentre as distintas fontes de energia renovável, os resíduos agrícolas proporcionam um grande potencial energético, contribuindo com o meio ambiente, os quais são transformados em briquetes.

Distintos materiais como os restos de colheita, ou propriamente sobras de produtos processados no meio rural, com seu dispor impróprio, causa problemas como a poluição e degradação dos solos e contaminação de afluentes, os quais provocam o desenvolvimento de vetores de múltiplas doenças. Com o reaproveitamento dos resíduos agrícolas encontra-se uma alternativa extra, estes servem como matéria-prima para a biomassa.

$\mathrm{Na}$ concentração da biomassa de resíduos sólidos causados pelo processo de limpeza e secagem de grãos, o resíduo se da à produção do briquete, o qual tem como competidor direto a lenha ou carvão de origem vegetal, obtém vantagem competitiva por ser um produto 
ecologicamente limpo, composto apenas por resíduos agrícolas de origem vegetal. O bom emprego dos resíduos não é rotina dos brasileiros, ainda se encontra grande resistência. $O$ hábito de reutilização de resíduos pretende-se introduzir aos poucos no comércio, tomando como exemplos indústrias que têm no seu planejamento estratégico uma economia de gastos com aquisição de lenha e ainda a destinação ambientalmente apropriada dos resíduos, resolvendo dificuldades ambiental e energética, segundo SILVEIRA (2008).

Ainda o autor Silveira (2008) define fonte de biomassa como todo e qualquer material orgânico que está disponível em um embasamento renovável ou mesmo recorrente, o que compreende nas seguintes situações, incluindo as colheitas de commodities, fruto da agricultura e silvicultura como restos de árvores, madeira e resíduos.

Biomassa no aspecto energético se refere a toda matéria orgânica, de procedência vegetal, a qual pode ser usada na produção de energia e certamente apresenta vantagens e desvantagens ao longo da cadeia.

Para o autor Grauer e Kawano (2001), o uso da biomassa, a qual é gerada pela silvicultura e agricultura na geração de energia, apresenta certos benefícios como baixo custo de aquisição, não liberação de dióxido de enxofre, o percentual de resíduos finos no formato de cinzas é de baixa agressividade ao meio ambiente comparada às provenientes de combustíveis fósseis, maior durabilidade dos equipamentos, risco ambiental baixo e é um recurso renovável.

Por outro lado apresenta certas desvantagens, como menor poder calorífico, relacionado com combustíveis à base de derivados de petróleo, maior probabilidade na geração de materiais particulados lançados no meio ambiente, exige custo de investimento em maquinários, para o processamento e principalmente para retirada de materiais particulados e a grande dificuldade no armazenamento da matéria-prima por exigir depósito fechado para acomodação (GRAUER e KAWANO, 2001).

De acordo com o autor Albuquerque (2010), quanto às vantagens do uso da biomassa, estas são inúmeras, principalmente no advento que vem surgindo como o mercado de carbono, disponibilidade da matéria-prima, a própria qualidade, tecnologia disponível para toda a cadeia do agronegócio no reaproveitamento para que a energia produzida a partir da biomassa tenha viabilidade econômica e ambiental.

Uma gestão eficiente proporciona a destinação adequada dos resíduos retirados no processo, tomar decisões levando em consideração aspectos, principalmente, financeiros, econômicos e sociais para beneficiar a própria empresa, tanto quanto a sociedade.

\section{Material e Métodos}


O trabalho foi realizado em uma Cooperativa no Município de Ponta Grossa - Paraná, o qual teve o intuito de avaliar o potencial de aproveitamento dos resíduos agrícolas para a produção de briquetes, com o objetivo de usar como fonte de energia, juntamente com lenha e cavaco nas caldeiras dos secadores de cereais.

Sendo assim, quanto à sua natureza a pesquisa é classificada como aplicada, a qual para Vergara (2007) se apresenta com intenção de definir um problema de importância prática e imediata. Também sobre pesquisa aplicada, Silva (2005) completa articulando que esta disposição de pesquisa aponta recursos para solução de problemas exclusivos ou específicos, envolvendo fatos de extrema importância e de locais.

Nesta pesquisa fez-se uso do método exploratório, para Gil (2009), a pesquisa exploratória tem a finalidade por uma abrangência maior do problema. Além disso, ajuda a auxiliar e a aprimorar ideias, apresenta seu planejamento bem flexível e geralmente submerge no levantamento bibliográfico e ao problema estudado.

Para a abordagem do problema, a pesquisa fica classificada como qualitativa. "A abordagem qualitativa de um problema, além de ser uma opção do investigador, justifica-se, sobretudo, por ser uma forma adequada. Tanto assim é que existem problemas que podem ser investigados por metodologia quantitativa" (RICHARDSON, 2009, p. 79).

Analisando ainda sobre a maneira de abordagem do problema, é admissível considerar o presente estudo como quantitativo. Silva (2005) ressalta sobre a pesquisa quantitativa como aquela que apresenta suas informações passíveis de serem demonstradas em números para posterior classificação e análise, fazendo uso de técnicas estatísticas.

Para Richardson (1999), tal artifício apresenta a finalidade de fornecer exatidão aos resultados, poupar distorções, produzir uma margem de garantia quanto às induções, ainda afirma que no processo de análise das informações, técnicas estatísticas cooperam na interpretação de ressalvas qualitativas.

Ainda o mesmo autor afirma que algumas pesquisas determinadas como descritivas, a partir das suas finalidades, ajustam-se para deparar um novo contorno de análise ao problema e isto as aproxima das pesquisas exploratórias. Com esse contorno pode-se, analisar que o presente estudo também seja, em parte, descritivo. De acordo com Silva (2005), a pesquisa descritiva proporciona a distinção de delinear características de determinada população ou acontecimento, relacionando variáveis.

Para a análise utilizaram-se os dados da produção e suprimentos. Os artifícios técnicos empregados neste estudo são: a pesquisa bibliográfica, compreendendo o referencial teórico. 
Gil (2009, p. 64) descreve como identificar fontes bibliográficas e as mais conhecidas:

Para identificar as fontes bibliográficas adequadas ao desenvolvimento da pesquisa, a contribuição do orientador é fundamental. Recomenda-se também a consulta a especialistas ou pessoas que já realizaram pesquisas na mesma área. Essas pessoas podem fornecer não apenas informações sobre o que já foi publicado, mas também apreciação crítica de material a ser consultado.

As fontes bibliográficas mais conhecidas são livros de leitura corrente. No entanto, existem muitas outras fontes de interesse para a pesquisa bibliográfica, tais como: obras de referência, teses e dissertações, periódicos científicos, anais de encontro científicos e periódicos de indexação e de resumo.

Por fim constitui-se em estudo de caso delineado de acordo com Roesch (2009), o estudo de caso é uma tática de pesquisa que busca interrogar um fato contemporâneo interno dentro do seu contexto e procura analisar uma situação específica. Nesse contexto, para Gil (2002, p.72), o estudo de caso pode ser "caracterizado pelo estudo profundo e exaustivo de um ou de poucos objetos, de maneira a permitir seu conhecimento mais amplo e detalhado [...]”.

Também foram organizados fluxograma do processo, quadros e tabelas realizadas para discussão dos resultados e a análise crítica do material. Foi possível ainda caracterizar os resultados obtidos durante o estudo.

\section{Resultados e Discussão}

Do resíduo resultante do processo de padronização de grãos existentes na unidade estudada, para uma destinação correta, surgiu a ideia de transformar em briquetes objetivando contribuir para os demais setores, os quais necessitam de matéria-prima para combustão, focando na redução de custos referente à geração de energia e principalmente o passivo ambiental através da destinação apropriada dos resíduos.

A preparação do resíduo começa com o peneiramento para retirar e reaproveitar os grãos que tenham sido descartados de maneira incorreta, eliminar partículas como terra, areia o próprio pó antes da secagem, moagem e compactação através da máquina (briquetagem) é uma opção não apenas para aplicar resíduos, mas sim para promover o transporte, armazenar, utilizar todo o resíduo originado durante a safra. O resíduo como matéria-prima é sazonal, acontece na colheita das commodities na safra de inverno, na cultura de trigo de outubro e novembro e a safra de verão, na cultura de milho e soja de fevereiro a maio.

A filial da Cooperativa em estudo apresenta como principal fonte para gerar energia a lenha de eucalipto e a demanda anual é em torno de 25.000 metros cúbicos. A busca para minimizar a demanda da própria lenha, principalmente por economia, levou a empresa a analisar o emprego de 
briquetes produzidos na própria unidade com o uso do resíduo.

Na Tabela 1 pode-se observar o consumo de lenha de eucalipto nos últimos quatro anos na unidade da Cooperativa estudada.

Tabela 1 - Consumo de lenha de eucalipto

\begin{tabular}{cccccc}
\hline & \multicolumn{5}{c}{ Consumo Lenha $\left(\mathrm{m}^{3}\right)$} \\
\hline UNIDADE/Ano & 2013 & 2012 & 2011 & 2010 & TOTAL \\
Ponta Grossa I & $11.742,49$ & $18.036,91$ & $12.862,52$ & $11.951,15$ & $54.593,07$ \\
Ponta Grossa II & $9.353,31$ & $11.327,72$ & $10.569,72$ & $13.660,49$ & $48.241,69$ \\
TOTAL GERAL & $21.095,80$ & $29.364,63$ & $23.432,24$ & $25.611,64$ & $102.834,76$ \\
\hline
\end{tabular}

Fonte: Batavo

Analisando a Tabela 1 referente ao consumo de lenha anual, considera-se alto e com o valor médio recente, a Cooperativa paga por metro cúbico $\mathrm{R} \$ 49,00$, o que acarreta um alto custo para secagem de grãos, ainda não está incluso transporte interno da lenha e pessoal envolvido no processo. Por essa demanda surgiu a ideia de reaproveitar a estrutura para reutilização de resíduos diminuindo custos com a lenha.

Como a Cooperativa já dispunha do local praticamente com toda estrutura entre barracão, secadores rotativos, moinhos que estava parada desde a compra da unidade em 2005, para dar andamento foi realizada a revisão de todo maquinário existente, ainda o investimento na compra de uma máquina briquetadeira de pistão mecânico com capacidade de produção de 2 ton./hora.

Para o desenvolvimento do projeto a estrutura da unidade de briquetes é composta com os seguintes equipamentos:

Tabela 2 - Estrutura para briquetagem de resíduos

\begin{tabular}{cl}
\hline Quantidade & \multicolumn{1}{c}{ Descrição } \\
\hline 1 & Prédio com $1.846 \mathrm{~m}^{2}$ com paredes de concreto armado, estruturas e \\
1 & coberturas metálicas altura $21 \mathrm{~m}$, com túnel de descarga. \\
1 & Máquina Tatu carregador \\
2 & Máquina de pré-limpeza dupla com peneiras n. 05/06 \\
2 & Secadores rotativos de resíduos \\
2 & Moinhos de martelo c/ motor $100 \mathrm{cv}$ e moegas metálicas \\
3 & Exaustor c/ motor 50 e 20 cv \\
2 & Transp. Helicoidal 5m descarga resíduos dos moinhos \\
1 & Briquetadeira B 85/210 \\
1 & Peças e acessórios aplicados na unidade de produção de briquetes B 85/210 \\
1 & Trua metálica modelo TR 315 \\
1 & Medidor de umidade \\
1 & Sonda tipo copo \\
\hline Fonte: Batavo 2013
\end{tabular}

A estrutura para fazer a briquetagem de resíduos agrícolas é composta como descrita na 
Tabela 2, a compactação do resíduo acontece por golpes produzidos que são acionados por dois volantes, os resíduos têm na sua composição principal: grãos chochos, cascas, terrões, palhas, sementes de plantas daninhas, obtidos no momento em que se realiza a pré-limpeza dos grãos antes da secagem e a limpeza antes do armazenamento.

Para um melhor entendimento sobre o processo de briquetagem de resíduos foi elaborado um fluxograma simples e de fácil entendimento, envolvendo todas as interfaces do início ao fim do processo.

O Fluxograma 1 da unidade de briquetagem envolvendo área construída e todo maquinário.

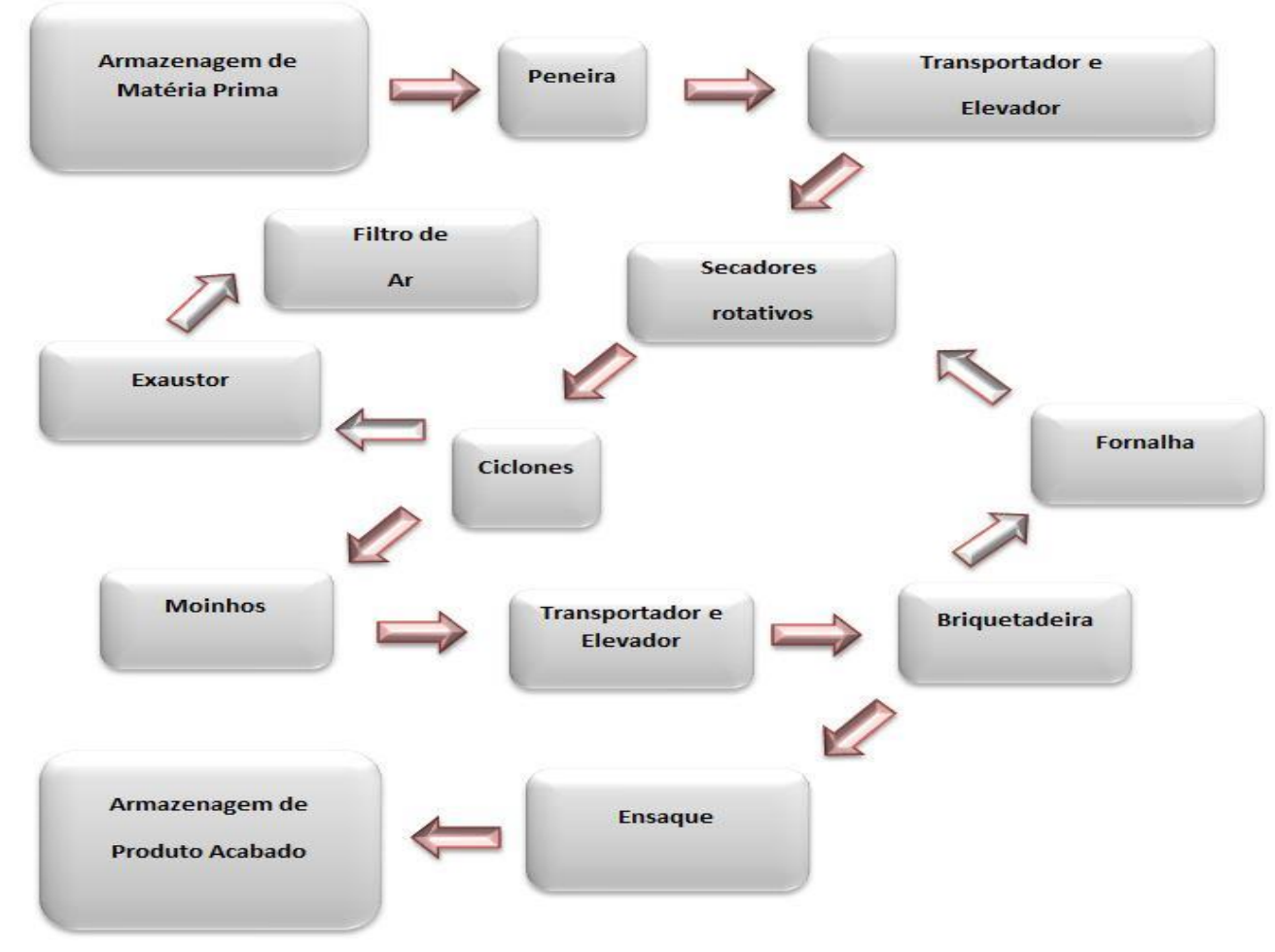

Fonte: próprio autor (2013)

O início do processo da transformação de resíduos em briquetes está no transporte dos resíduos agrícolas originados no setor armazém e secadores da Cooperativa para a unidade de briquetes, sendo todo pesado esse material para controle de entrada e saída do envio do resíduo e no modal a granel, descarregado em área coberta dentro do barracão localizado no fluxograma como matéria-prima.

Com a matéria-prima armazenada no local, dá-se início a preparação do resíduo para briquetar, passando pela peneira para a separação do produto soja que está no lixo, também as impurezas mais finas como terra, areia que intervêm na briquetagem.

O primeiro ensaio com resíduo, em torno de $26 \%$ de umidade, segue para o elevador, o qual transporta para o secador rotativo, com fornalha de aspiração forçada alimentada à lenha e 
posteriormente com a própria produção de briquetes, a umidade do próprio resíduo é diminuída para ficar em torno de $11 \%$ a $14 \%$, a secagem é considerada contínua, a saída da mistura do secador rotativo acontece por sucção causado por dois exaustores, que conduzem a mistura para o ciclone com eclusa, para separar o ar dos fragmentos do resíduo, seguindo para a trituração no moinho de martelos, para compactação e homogeneização da mistura, o produto é retirado por rosca helicoidal e transportado até o elevador, que alimenta a máquina de briquetagem, esta é composta por uma prensa com pistão mecânico, que causa a compressão da mistura com grande pressão, gerando aumento da temperatura na mistura que reúne as partículas desenvolvendo o briquete resfriado que, ao longo do tubo de saída até o ensaque, ganha aproximadamente um diâmetro de $70 \mathrm{~mm}$ e comprimento de aproximadamente $8 \mathrm{~cm}$.

Para o autor Lippel (2013, p.1), a conceituação de briquetes se apresenta como:

Produto de alto teor calorífico, obtido pela compactação dos resíduos de madeiras como o pó de serragem e as cascas vegetais, geralmente provenientes do desdobramento de tora. É considerado uma lenha ou carvão ecológico de alta qualidade, feito a partir da compactação de resíduos ligno-celulósicos, só pressão e temperatura elevada, tais como: galhos e cascas de árvores, aparas de madeira, serragem, pó de lixa, maravalhas, bagaço de cana -de-açúcar, casca de arroz, palha e sabugo de milho etc.

O primeiro experimento infelizmente não foi satisfatório por não produzir um briquete compacto com massa sólida, esfarelou muito e ficou sem estrutura ideal para alimentar caldeiras com alta temperatura, gerando muita cinza na queima ficando esta acumulada no interior das caldeiras.

O segundo experimento foi realizado misturando uma proporção de serragem de madeira com um percentual aproximado de $80 \%$ de resíduos e $20 \%$ de serragem no processo, com a serragem e resíduos juntos, a umidade inicial ficou em torno de $38 \%$, seguindo o mesmo fluxo acima mencionado, a umidade da mistura resíduo/serragem foi diminuída para ficar em torno de $11 \%$, a 14\% para um produto acabado com melhor valor energético e estrutura adequada.

Segundo Lippel (2013, p. 2) a secagem de resíduos para briquetagem consiste:

Em média, os resíduos de madeira ou agrícolas apresentam 45 a 50\% de umidade. Para que o processo de briquetagem tenha efeito, a secagem deverá ser executada a um percentual médio de 10 a 16\%, dependendo dos tipos de biomassa.

A serragem de madeira é constituída de subprodutos de serrarias resultantes do corte da madeira e durante o processo de acabamento para madeira. Utilizada no processo como aglutinante para melhorar a consistência do briquete, sendo adquirida de serrarias da região, com o preço médio por $\left(\mathrm{m}^{3}\right)$ de $\mathrm{R} \$ 17,00$. 
Com a dosagem de serragem no resíduo, o briquete ficou satisfatório, com massa sólida bem compactada, esse produto não esfarela, resfriado ganha aproximadamente um diâmetro de $70 \mathrm{~mm}$ e comprimento de aproximadamente 30 a $40 \mathrm{~cm}$. Para alimentar caldeiras seu aproveitamento foi satisfatório, gerando pouca cinza e resíduo no interior da caldeira em mistura com cavaco na fornalha.

Esse material é acondicionado manualmente em sacos de papel com $10 \mathrm{~kg}$, que são costurados e acondicionados em pellets envolvidos com papel stretch até expedição final, garantindo a qualidade e fácil movimentação com empilhadeira.

Algumas das vantagens do uso de briquetes para Lippel (2012) apud Fernandes (2012, p. 5) são:

O briquete possui muitas vantagens, ambientais e econômicas, fazendo dele um grande diferencial e uma alternativa forte para a substituição da lenha e do carvão vegetal: É totalmente liberado pelo IBAMA, dispensa guia e reposição florestal junto ao órgão fiscalizador, é uma energia limpa, pois possui menor índice de poluição comparado a outros combustíveis, é uma fonte de energia renovável, tem alto valor agregado, está pronto para a queima, ou seja, não precisa de preparação ou equipamento especial, tem alto poder calorifico, é de fácil manuseio, armazenamento e transporte e tem um melhor custo/benefício. Além de todas essas vantagens, ele é vendido por peso, já a lenha é comercializada por $\mathrm{m}^{3}$, o que permite perdas devido aos vazios em seu empilhamento. $\mathrm{O}$ briquete, por sua vez, também permite um menor espaço de armazenagem devido a sua facilidade no manuseio, porém, há um cuidado que deve ser tomado: na estocagem, ele deve ser guardado em ambiente seco e arejado, em cima de palletes, para ser isolado da umidade do chão.

Ainda para Lippel (2012) apud Fernandes (2012, p.5) há algumas desvantagens para briquetes feitos com resíduos agrícolas:

\begin{abstract}
Os briquetes de segunda linha são feitos com resíduos agrícolas que, apesar de ter bons níveis de energia, apresentam menor aproveitamento na queima e podem causar problemas nas fornalhas/caldeiras por este motivo, além de gerar maior volume de fumaça e fuligem. Mesmo assim, têm utilização garantida, principalmente em regiões do Brasil onde a matéria-prima para fabricação do briquete de melhor qualidade é escassa e o valor do frete é elevado, como se observa em alguns estados do Nordeste brasileiro. Nessas regiões, onde há uma grande produção e utilização de cana, devido à produção de açúcar e álcool, produz-se briquete com bagaço de cana, ou seja, a cana depois de ser utilizada. Desta forma, há reaproveitamento do resíduo e atinge aos mesmos mercados das cidades que usam o de madeira.
\end{abstract}

Para a Cooperativa estudada, o briquete se destaca como vantagem competitiva principalmente da matéria-prima (resíduo), a qual elimina um enorme passivo ambiental e a retirada da soja que vai junto com o resíduo. Apresenta-se a seguir na Tabela 3, a quantidade de reaproveitamento no período de fevereiro a maio, quando se encontra a matéria-prima por ser safra, com a colheita da commodity soja. 
Tabela 3 - Soja retirada no processo para briquetagem

\begin{tabular}{cc}
\hline Produto & 2013 (ton.) \\
\hline Soja & 89.38 \\
\hline
\end{tabular}

Fonte: Próprio autor (2013)

Analisando em valor monetário, a soja praticamente já descartada como lixo, retirada no processo de peneiramento da matéria-prima para fazer briquetes, voltou para soja normal, fazendo uma receita com o valor médio da saca de $\mathrm{R} \$$ 65,00, ficando um total de $\mathrm{R} \$ 96.798,54$, é um número considerado que ajuda a pagar a máquina antes do tempo estimado. Ainda analisando a quantidade de matéria-prima que surge durante todo o processo de limpeza e secagem de grãos, os dados apontados na tabela 4 foram alcançados no início de fevereiro até julho de 2013.

Tabela 4 - Disponibilidade de matéria-prima: resíduo de soja e serragem e briquete sendo produto final.

\begin{tabular}{cc} 
Matéria-prima & 2013 (ton.) \\
\hline Resíduo Soja & 993.60 \\
Serragem & 58.84 \\
Total Matéria-prima & 1.052 .44 \\
Produto final Briquetes & 814.24 \\
\hline
\end{tabular}

Fonte: Próprio autor (2013)

Analisando os dados da tabela quanto aos volumes de matéria-prima que seriam considerados como lixo no primeiro semestre de 2013, percebe-se a quantidade de resíduo de soja reaproveitada gerando energia limpa. $\mathrm{O}$ custo com a compra de serragem de madeireiras da região teve um gasto de $\mathrm{R} \$ 3.969,00$.

Consumo de lenha de eucalipto na secagem de grãos, relacionando tonelada $\mathrm{x}$ metro cúbico de lenha, explanando melhor entendimento do assunto, significa que para uma tonelada de grãos há um gasto de $0.10 \mathrm{~m}^{3}$ a $0.13 \mathrm{~m}^{3}$ de lenha.

Para uma melhor comparação de energia gasta lenha $\mathrm{x}$ briquete juntos, a Tabela 5 esboça $\mathrm{o}$ consumo efetivo.

Tabela 5 - Quantidade produto x consumo lenha e briquete

\begin{tabular}{cc}
\hline Produto & 2013 \\
\hline Soja (ton.) & 100 \\
Lenha (m $\left.{ }^{3}\right)$ & 7.32 \\
Briquetes (ton.) & 2.12 \\
\hline
\end{tabular}

Fonte: Próprio autor (2013) 
Visualizando a tabela, demonstra-se sem dúvida a economia de lenha. Para 100 toneladas foram consumidos $7.32 \mathrm{~m}^{3}$, só com lenha teria um consumo aproximado $11 \mathrm{~m}^{3}$, com esse experimento houve uma economia em valor monetário de $\mathrm{R} \$ 180,32$ com o consumo de lenha, analisando o total da produção recebida na unidade de produto para secagem, teria aproximadamente um consumo de $12.600 \mathrm{~m}^{3}$ da lenha em conjunto com a queima de briquete, o consumo de lenha ficou em torno de $9.353,31 \mathrm{~m}^{3}$, a economia de lenha ficou aproximado de 3.200 $\mathrm{m}^{3}$, transformando em valor monetário, a custo médio de $\mathrm{R} \$ 49,00$, o metro total fica com $\mathrm{R} \$$ 156.800,00 de economia.

\section{Conclusões}

O tema proposto neste trabalho mostrou a importância da destinação correta dos resíduos gerados durante o processo de padronização das commodities para a Cooperativa que trabalha com prestação de serviços, o resíduo retirado do produto se torna um passível ambiental; para dar o destino correto dos resíduos agrícolas, agregando valor, como já tinha toda estrutura, a Cooperativa analisou o investimento na revisão do maquinário existente e na compra da máquina para briquetagem.

Diante da situação foi verificado o volume de resíduos que surge durante o processo de padronização de grãos na Cooperativa, mediante a quantidade da matéria- prima apurada, que somou um total de 993.60 toneladas de resíduos, foi traçado o segundo objetivo: analisar a estrutura existente na Cooperativa para confecção de briquetes, mediante a revisão de todo equipamento e a compra da máquina briquetadeira. Com tudo instalado, rodando perfeitamente, foi a vez de avaliar a destinação dos resíduos, os quais são transformados em briquetes ou lenha ecológica.

Após alguns experimentos que não foram satisfatórios, entre o acerto da dosagem de resíduo e serragem houve certo desequilíbrio, com pensamentos de que a experiência não daria certo, mas mediante troca de informações com outras empresas, foi possível estabelecer um critério de dosagem da serragem junto com o resíduo de soja, que foi trabalhado gerando uma produção de 814.24 toneladas de briquetes, os quais foram consumidos na própria unidade, na secagem das commodities, ainda houve uma transferência para outra filial da Cooperativa para alimentar caldeiras, gerando uma receita no valor de R\$165,00 a tonelada.

Com o reaproveitamento da soja na quantidade de 89.38 toneladas, descartada irregularmente durante o processo e que iria para o lixo, conseguiu-se um valor significativo, fazendo uma receita com o valor médio da saca de $\mathrm{R} \$ 65,00$, ficando um total de $\mathrm{R} \$ 96.798,54$, foi um número considerável que ajuda a pagar a máquina antes do tempo estimado.

Para a queima do briquete ou lenha ecológica em caldeiras de secadores de commodities, 
juntamente com cavaco e a própria lenha, seu valor energético é eficaz, economizando cerca de $30 \%$ do consumo direto da energia não renovável.

Ficou constatada a economia de lenha e principalmente de valor monetário com o experimento feito em 100 toneladas de grãos com a queima de briquete ou lenha ecológica, que foi queimando 7.32 metros cúbicos de lenha mais duas toneladas de lenha ecológica. Sem a queima do briquete em conjunto com a lenha, essa quantidade de lenha queimada ficava em torno de 11 metros cúbicos, no valor total de $\mathrm{R} \$ 539,00$, com a mistura de briquete $\mathrm{x}$ lenha, esse custo caiu para $\mathrm{R} \$$ 358,68 , gerando uma economia em valor monetário de R\$180,32.

Analisando as vantagens e desvantagem do uso de briquetes para secagem de commodities percebeu-se a soma das vantagens na utilização da lenha ecológica como: energia limpa, totalmente sem restrições ao uso por órgãos de fiscalização, eliminação de passível ambiental para a Cooperativa entre outros benefícios.

Os objetivos traçados inicialmente neste estudo foram alcançados, devido ao embasamento teórico dos autores, que forneceu a teoria necessária para realização da pesquisa, também foram apresentados no resultado da pesquisa os dados sobre a avaliação de aproveitamento dos resíduos agrícolas para a produção de briquetes ecológicos.

Por fim, o presente estudo se coloca como ajuda para posteriores pesquisas sobre o tema do reaproveitamento de resíduos agrícolas para fazer briquetes, a verdadeira lenha ecológica, com intuito de motivar novas e ainda mais profundas pesquisas.

\begin{abstract}
This work evaluated the potential use of agricultural waste into a Cooperative in the city of Ponta Grossa - Parana. The work raises issues about agribusiness, agro-industrial waste, biomass, renewable energy, ecological firewood, recycling of waste and production of briquettes. For a greater understanding and enrichment of the research were discussed such matters as the origin of agricultural residues, raising the volume of waste, processing waste into briquettes, reuse of soybean by problems in the process has been discarded as trash, evaluation of existing unit in the cooperative for briquetting, lately, was evaluated the burning of briquettes with splinter and firewood. The use of agricultural waste as biomass fuel for power generation transformed into briquettes can be a solution to the problems related to them. This study is based on research technique, classifying it as basic, exploratory qualitative, using as technical procedures the literature review and case study. This study aimed to verify the amount of waste that arises during the process of standardization of grains in the Cooperative, analyzing the existing structure in the cooperative for making briquettes and, finally, evaluates the waste disposal which is processed into briquettes. With these results it was proved that the reuse of waste considered as junk, was of utmost importance as renewable energy, saving money and the correct destination for the Cooperative that works with services in the standardization of commodities, was eliminated likely environmental, adding value, as had all the structure, the company revised and bought the machine for briquetting.
\end{abstract}

Key-words: waste, briquettes, renewable energy

\title{
Referências
}

ALBUQUERQUE, J. L. Gestão Ambiental e Responsabilidade Social: Conceitos, Ferramentas e Aplicações. São Paulo: Atlas, 2010.

ABIB. Disponível em: http://associacaobrbiomassa.blogs.sapo.pt/897.html. 2010. Acessado em 20 de agosto de 2013. 
BATALHA, M.; O. Gestão agroindustrial. São Paulo: Atlas, 1997.

FARAGE, R. M. P. Aproveitamento dos resíduos lignocelulósicos gerados no Polo Moveleiro de Ubá para fins energéticos. Dissertação (Mestrado em Engenharia Ambiental, área de concentração em Meio Ambiente) Universidade Federal de Ouro Preto, Ouro Preto, 2009. Disponível em: http://www.tede.ufop.br/tde_busca/arquivo.php?codArquivo=588. Acessado em 01 de agosto de 2013.

FERNANDES, C. R. P.; AUgusto, A. P.; SANTOS, I. J. S. D.; SOUZA, S. C. D. PRODUÇÃO DE BRIQUETE INDUSTRIAL: ENERGIA LIMPA E SUSTENTÁVEL 2012. Instituto Federal de Educação, Ciência e Tecnologia do Rio Grande do Norte, Estudante do Curso Técnico Integrado de Controle Ambiental. 2012. Disponível em http://www.ibeas.org.br/congresso/Trabalhos2012/X-007.pdf. Acessado em 01 de outubro de 2013.

GIL, A. C. Técnicas de pesquisa em administração e elaboração de monografias. São Paulo: Atlas, 2002.

GIL, A. C. Como elaborar projetos de pesquisa. 4. ed. São Paulo: Atlas, 2009.

GOldemberg, J. Pesquisa e Desenvolvimento na área de energia. São Paulo em Perspectiva, São Paulo, v.14, n.3, 2000 .

GRAUER, A.; KAWANO, M.. Uso de biomassa para produção de energia. Boletim Informativo da Bolsa de Reciclagem, v.1, n. 5. 2001.

JUNIOR, A. F. T.; GUIMARÃES, J. L. S.; SANTOS, G. A.; LEITE, A. M. F.; BARROS, G. D. T. Utilização de biomassa para briquetagem como fonte de energia alternativa e a disponibilidade deste recurso na região do Cariri-CE. Disponível em: http://www.abepro.org.br/biblioteca/ENEGEP2003_TR1003_0215.pdf. Acessado em 23 de agosto de 2013 .

LIPPEL. Planejando usina de briquetagem. 2013.

MOERS, E. M.; VIEIRA, A. C.; FERNANDES, D.M.; SOUZA S. N. M.; BARICATTI, R. A. Caracterização da biomassa residual proveniente de resíduos agrícolas para geração de energia. I COLASSA - Congresso Latino Americano de Suinocultura e Sustentabilidade Ambiental. Foz do Iguaçu, PR. 2011.

QUIRINO, W. F. Utilização energética de resíduos vegetais. Laboratório de Produtos Florestais - LPF/IBAMA. Brasília, 2003.

RICHARDSON, R. J. Pesquisa social: métodos e técnicas. 3 ed., São Paulo: Atlas, 1999.

RICHARDSON, R. J. Pesquisa social: métodos e técnicas. 3 ed., São Paulo: Atlas, 2009.

ROESCH, S. M. A. Projetos de estágio e de pesquisa em administração: guia para estágios, trabalhos de conclusão dissertações e estudos de caso. 3. ed. São Paulo: Atlas, 2009.

ROSA, M. F.; SOUZA F. M. S. M; FIGUEIREDO M.C.B.; MORAIS J.P.S.; SANTAELLA S.T.; LEITÃO R.C. Valorização de resíduos da agroindústria. II Simpósio internacional sobre gerenciamento de resíduos agropecuários e agroindustriais - II SIGERA: Volume 1: Palestras. Foz do Iguaçu, PR. 2011.

SILVA, E. L. D. Metodologia da pesquisa e elaboração da dissertação. 4. ed. Florianópolis: UFSC, 2005.

SILVEIRA, M. S. Aproveitamento das cascas de coco verde para produção de briquetes em Salvador-BA, 2008. Mestrado Profissional em Gerenciamento e Tecnologias Ambientais no Processo Produtivo - Ênfase em Produção Limpa - Escola Politécnica, Universidade Federal da Bahia, Salvador. Disponível em: $<\mathrm{http}$ ://www.teclim.ufba.br/site/material_online/dissertacoes/dis_monica_silveira.pdf $>$ Acesso em 09 de agosto de 2013.

VALE, A. T.; GENTIL, L. V. Produção e uso energético de biomassa e resíduos agroflorestais. In: Tecnologias aplicadas ao setor madeireiro III. Rio Branco: Suprema, 2008.

VERGARA, S. C. Projetos e relatórios de pesquisa em administração. 9. ed. São Paulo: Atlas, 2007.

Submetido em 28 nov. 2013, Aceito para publicação em 11 jan. 2015, Publicado em 10 dez. 2015. 